\title{
Comparison of Four Different Methods of the Ant Colony Optimization Algorithm Applied to Crew Dispatch for Network Services in an Electricity Utility
}

\author{
Paulo Baumann1, Tiago Miranda1, Fabio Romero1, João Castilho Neto1, Alden Antunes1, Dário \\ Takahata1, Leonardo Ferreira Neto1, Angelo Alves2, Luisa Azevedo2, Sérgio Valinho2
}

\begin{abstract}
This paper shows the application of Ant Colony Optimization for the dispatch of crew teams for service assistance in an electricity utility. Four variations of the optimization algorithm are tested: sequential, deterministic-concurrent, random-concurrent and simultaneous. The methodology takes as input a set of service calls and the importance of assisting each of them. The algorithm is able to create the routes to be taken by each team and the sequence in which the services will be assisted taking into account the benefits of assisting a certain service as well as the impact of not assisting it. A computer program was developed to apply these methods and the results were considered better than the ones from the current methods used by the Company. Also, it is more suitable for real time daily applications. Finally, the four variations are compared.
\end{abstract}

Keywords - Ant colony optimization, crew dispatch, service assistance.

\section{INTRODUCTION}

$\mathrm{T}_{\mathrm{D}}^{\mathrm{H}}$ HE study presented on this paper is part of a Research and Development (R\&D) Project of ANEEL (Brazilian Electricity Regulatory Agency), developed jointly by Electricity Company of Maranhão (CEMAR) and Daimon Engineering \& Systems. CEMAR is a private-owned electric distribution utility, located in the northern region of Brazil which supplies over 2,000,000 customers, in the state of Maranhão, in Brazil.

Currently, at CEMAR (and at many other Brazilian electric companies), just a few variables are taken into account by the Company's dispatchers when service assistance is needed. They make their decisions based on previous knowledge, usually intuitively or by ad hoc methods. Also, the decisions are not reevaluated even if the circumstances are different.

In order to select the services to be assisted, its sequence and the route to be taken by each available team, a

Firstname SurnameAuthor ${ }^{1}$ is with the National Institute of Standards and Technology, Boulder, CO 80305 USA (corresponding author's phone: ; e-mail: $\quad$ ).

Firstname SurnameAuthor ${ }^{2}$, was with Rice University, Houston, TX 77005 USA. He is now with the Department of Physics, Colorado State University, Fort Collins, CO 80523 USA (e-mail: ).

Firstname SurnameAuthor ${ }^{3}$ is with the Electrical Engineering Department, University of Colorado, Boulder, CO 80309 USA, on leave from the National Research Institute for Metals, Tsukuba, Japan (e-mail: consolidated meta-heuristic method was implemented: The Ant Colony Optimization (ACO) algorithm. Four variations of it were implemented and compared: sequential, deterministicconcurrent, random-concurrent and simultaneous [1].

The product developed offers to CEMAR and also to the technical community and to the society some important solutions and tools that are not yet contemplated by the current systems, making it an original project. It is a sophisticated tool that makes the most suitable decision for crew dispatch.

This paper is organized in a way that the next section presents the theoretic bases of the project, the ACO metaheuristic method. On Section III, the methodology is described. Section IV shows and discusses the results and, finally, Section V concludes the paper.

\section{ANT COLONY OPTIMIZATION}

The Ant Colony Optimization (ACO) belongs to a metaheuristic group based on populations. This method can be used to solve the crew dispatch problem, in which there is a set of places to be visited and, in each of them, there is a prize to be taken by the visiting team. Once a team arrived at the point and receives the prize, no other team can receive it. The goal is to maximize the total prize [1].

This technique was inspired by the fact that ants from a colony guide themselves by a track of pheromones, searching for the best path to their food source. Good tracks are chosen more often, making its pheromone concentration greater as well as the likelihood of it being chosen again. However, some ants can explore other possibilities trying to find paths that are even better [1].

The problem can be presented as a graph. The service locations are the vertices and the paths are the edges. In ACO algorithms, an ant represents a solution. When constructing a solution, each ant is put on a starting point and then wanders randomly from vertex to vertex in the graph. At each vertex, an ant probabilistically selects the next vertex according to a decision policy or transition rule, which depends on the pheromone trails and on the heuristic information on the edges and vertices. Also, they deposit pheromone in the edges in order to attract other ants towards the corresponding area of the search space. The pheromones can evaporate, allowing some past history to be forgotten, and helping diversify the 
search to new and hopefully more promising areas of the search space [1].

During the construction of a solution, an ant chooses a feasible path for each vehicle (a crew team). The choice method depends on the variation of the ACO algorithm to be used. There are four variations: sequential, deterministicconcurrent, random-concurrent and simultaneous [1].

\section{A. Sequential}

In this case, firstly an ant chooses a vehicle and selects a path for it according to the pheromone tracks and the heurist. A different vehicle will only be taken when there are no more feasible vertices to be visited by the first one [1].

\section{B. Deterministic-Concurrent}

In this situation, after choosing a vehicle-vertex pair (according to the pheromone tracks and the heuristic), an ant can take another vehicle. The vehicle choosing procedure is deterministic, which means the sequence of the vehicles is previously fixed. For each vehicle, the feasible vertices are identified and one is chosen according to its likelihood. Then, the next vehicle is selected and the procedure continues until there are no more feasible vertices for a vehicle [1].

\section{Random-Concurrent}

This case is very similar to the deterministic-concurrent. The only difference is the procedure in which the vehicles are chosen. Here, the next vehicle is randomly chosen [1].

\section{Simultaneous}

At first, all the feasible vehicle-vertex pairs are considered. Then, the probability of each pair is calculated according to the pheromone tracks and the heuristic. Thus, one of these pairs is chosen respecting its probability. After, the problem constraints are verified and the set of vehicle-vertex pairs are updated. The process goes on until there are no more feasible pairs [1].

For all the cases, a fixed number of ants/solutions is predefined within a cycle (the amount of cycles is also defined previously). A solution consists of a set of routes, one for each vehicle/team. In a cycle, all ants independently try to find the better routes for the vehicles. In the next cycle, its ants will be influenced by the pheromones left by the ones from the previous cycles. At the end of the process, the solution that maximizes the prize is chosen [1].

\section{Methodology}

\section{A. The System}

The system's goal is to attribute the service calls (SCs) to the most suitable available crew teams taking into account the benefits of assisting a certain service as well as the impact of not assisting it.

The attribution must take into account some parameters. They are: the execution average time by service and by team, team location, acting area, expected travel time, maximum and minimum Standard Service Unities (SSUs - it is a time unity used to measure the duration of service assistance of the team crews, varying from team to team according to the average travel time in its acting area) to be accomplished, team shift duration, availability, connectivity, vehicle type, vehicle traction type and team costs matrix.

The characteristics of the region assisted by CEMAR and of the Brazilian electricity system require some rules that must be considered by the dispatch system. They are:

- Team dispatch for supply interruption services due to non-payment must occur at a pre-defined time or as close to this as possible, if not possible;

- Services that are manually assigned to a team must me assisted first;

- No service can interfere in another that is currently being assisted;

- Supply interruption services due to non-payment must be done until a pre-defined time. The SCs that cannot be assisted by that time will be placed at the end of the route. However, for route construction and solution comparison it is considered they will not be assisted;

- Each team must assist a minimum and a maximum of SSUs;

- The feasibility of the assistance of a SC by a team is defined in the price book (a table that defines the assisting costs by service type, crew team and area) or in the team's parameters;

- Temporary new connections cannot be done before 1 hour of the scheduled time;

- Temporally connections must occur between 1 hour before the scheduled time and the schedule time;

- Crew teams can change vehicles just in case of accident or bad operation. In this case, the team will be set as nonavailable, the dispatch manager will close its shift e then will initiate a new shift with the associated new vehicle;

- SCs whose opening reason is in a pre-defined list will not be assigned by the system. The operator will do it manually;

- The cutoff location must be evaluated when dispatching teams for reconnection services;

- An increment on the cost matrix must be considered when teams with no traction vehicles assist services in country areas;

- Supply interruption services due to non-payment can be allocated in a group according to their coordinates and types and will be assisted by one team only;

- A regional possess many operational base that can assist many towns or part of a city. Teams can assist all the operational base extension, but they should be dispatched preferentially to where they have more experience;

- Solutions in which a team could not achieve its production target must not be considered;

- The standard service duration, measured in SSU, varies according to service, team and regional;

- Temporary cutoff must be done after the scheduled time;

- The lunch break duration is of 2 hours, from $12 \mathrm{pm}$ to $2 \mathrm{pm}$;

- Commercial SCs can be assisted at any time;

- A SC must be located in the team acting area;

- The team must be able to assist the SC (according to its cost matrix); 
- The team must be available;

- The team must be able to receive messages from the operator, and;

- The vehicle used by the team must suit the SC.

In order to estimate the time to be spent by a team for the assistance of the assigned SCs and make sure it can start assisting the last SC before the end of the shift, it is necessary to measure the assistance duration and travel time. The assistance duration will be estimated by the average time spent by the team in that type of service. The distances and travel times between SCs are calculated using mapping web tools, like Google Maps. Alternatively, the linear distance between the coordinates and the average speed can be used to calculate the travel time.

The system assumes the existence of a previous system able to define the SC's importance. Also, in some days, there will be SCs that will not be assisted. Knowing that, the most important SCs should be assisted preferentially.

\section{B. The Solution}

A solution is valid if it defines a set of routes containing the $\mathrm{SCs}$ to be assisted by a team observing the previously mentioned rules. The best solution will be the one that minimizes the sum of the importance of the non-assisted SCs (X) and minimizes the sum of the assisted SCs (Y) respectively. These values will be presented in the next section in separated brackets like this: $[\mathrm{X} \mid \mathrm{Y}]$.

The lexicographic method will be used here. In this method, capable of finding an optimal solution, it is given maximum importance to the first target (minimizing the sum of the importance of the non-assisted SCs). In case just one solution is found when minimizing the first function, it is chosen and the other targets are not evaluated. In case there are multiple solutions, the next step is to minimize the second most important target. From the second minimization, a new constraint is considered to make sure the value from the previous target does not increase [2].

\section{RESUlTS}

Two fictitious and simplified situations have been proposed in order to illustrate the results that can be obtained by the new methodology. In all of them some SCs were created in order to be met by 3 crew teams. The SCs have been prioritized

TABLE II

LIST OF PENDING COMMERCIAL SERVICES

\begin{tabular}{|c|c|c|c|c|c|}
\hline $\begin{array}{l}\text { Commercial } \\
\text { services (all } \\
\text { reconnection) }\end{array}$ & $\begin{array}{l}\text { Client im- } \\
\text { portance }\left({ }^{1}\right)\end{array}$ & $\begin{array}{l}\text { Type of } \\
\text { request }\end{array}$ & $\begin{array}{c}\text { Client's average bill } \\
\text { (US\$) }\end{array}$ & $\begin{array}{l}\text { Process started } \\
\text { (hours) }\left(^{2}\right)\end{array}$ & $\begin{array}{c}\text { Deadline } \\
\text { (hours) }\end{array}$ \\
\hline 13 & S & Ordinary & $5,000.00$ & 24 before & 8 \\
\hline 14 & $\mathrm{~S}$ & Ordinary & $5,000.00$ & 3 after & 32 \\
\hline 15 & $\mathrm{~S}$ & Ordinary & $5,000.00$ & 6 after & 32 \\
\hline 16 & $\mathrm{~S}$ & Judicial & $5,000.00$ & 18 before & 32 \\
\hline 17 & $\mathrm{~S}$ & Ordinary & $5,000.00$ & 24 before & 8 \\
\hline 18 & $\mathrm{P}$ & Ordinary & $5,000.00$ & 3 after & 32 \\
\hline 19 & $\mathrm{P}$ & Judicial & $5,000.00$ & 18 before & 32 \\
\hline 20 & $\mathrm{P}$ & Judicial & $15,000.00$ & 24 before & 32 \\
\hline 21 & $\mathrm{~S}$ & Ordinary & $15,000.00$ & 24 before & 32 \\
\hline 22 & $\mathrm{~S}$ & Ordinary & $15,000.00$ & 6 after & 32 \\
\hline 23 & $\mathrm{~S}$ & Ordinary & 500.00 & 24 before & 8 \\
\hline 24 & $\mathrm{~S}$ & Judicial & 500.00 & 24 before & 32 \\
\hline
\end{tabular}
effectiveness of the solutions.

The SCs are divided in three types as follows: to pay the electricity bills; connections, do reconnection after paying their debts etc.; customers and safety issues; explore the limitations of each of them.

\section{A. First Situation} SC are specified on Tables I, II and III:

TABLE I

LIST OF PENDING SUPPLY INTERRUPTION SERVICES

$\left({ }^{1}\right)$ Dispatch time: 09:00 a.m. on December 5th 2015

(1)

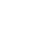

previously and an index was calculated to measure the

a) Supply interruption services due to non-payment: Disconnection procedures applied to the customers who failed

b) Commercial services: These are service orders requested by the consumers for instance, to check their meters, do new

c) Supply restoration services: These are technical service orders, primarily to reestablish energy supply after a fault. In short, emergency orders have to do with disconnection of

d) The first situation will focus on comparing the current method to the new one with its 4 possible variations. The second one will compare just the $4 \mathrm{ACO}$ algorithms in order to

The first situation was created in order to compare the current method applied by CEMAR (basically intuitive with very simple restrictions) with the 4 ACO variations. Thirty-six SCs have been created and the 3 crew teams have the same characteristics and an 8 hours shift. The characteristics of each

\begin{tabular}{ccc}
\hline \hline $\begin{array}{c}\text { Supply interruption } \\
\text { services due to non- } \\
\text { payment }\end{array}$ & $\begin{array}{c}\text { Customer's } \\
\text { accumulated debt } \\
\text { (US\$) }\end{array}$ & $\begin{array}{c}\text { Process started before } \\
\text { dispatch (hours) }{ }^{1} \text { ) }\end{array}$ \\
\hline 01 & 200.00 & 24 \\
02 & 200.00 & 24 \\
03 & 200.00 & 18 \\
04 & 200.00 & 96 \\
05 & $1,000.00$ & 24 \\
06 & $1,000.00$ & 24 \\
07 & $1,000.00$ & 24 \\
08 & $1,000.00$ & 18 \\
09 & $5,000.00$ & 24 \\
10 & $5,000.00$ & 24 \\
11 & $5,000.00$ & 24 \\
12 & $10,000.00$ & 24 \\
\hline
\end{tabular}


TABLE III

LIST OF PENDING SUPPLY RESTORATION SERVICES

\begin{tabular}{cccccc}
\hline \hline $\begin{array}{c}\text { Supply restoration } \\
\text { services }\end{array}$ & $\begin{array}{c}\text { Clients im- } \\
\text { portance }\left({ }^{2}\right)\end{array}$ & $\begin{array}{c}\text { Com- } \\
\text { plaints }\left({ }^{1}\right)\end{array}$ & $\begin{array}{c}\text { Recalls } \\
\left({ }^{3}\right)\end{array}$ & $\begin{array}{c}\text { Reinci- } \\
\text { dences }\left({ }^{4}\right)\end{array}$ & $\begin{array}{c}\text { Process started before } \\
\text { dispatch }\left({ }^{5}\right)\end{array}$ (hours) \\
\hline 25 & $\mathrm{P}$ & $\mathrm{G}$ & 15 & 0 & 2 \\
26 & $\mathrm{P}$ & $\mathrm{G}$ & 10 & 2 & 2 \\
27 & $\mathrm{P}$ & $\mathrm{G}$ & 10 & 0 & 2 \\
28 & $\mathrm{~S}$ & $\mathrm{G}$ & 5 & 5 & 24 \\
29 & $\mathrm{~S}$ & $\mathrm{G}$ & 5 & 3 & 24 \\
30 & $\mathrm{~T}$ & $\mathrm{I}$ & 0 & 5 & 24 \\
31 & $\mathrm{~T}$ & $\mathrm{I}$ & 0 & 0 & 0 \\
32 & $\mathrm{~S}$ & $\mathrm{I}$ & 0 & 0 & 19 \\
33 & $\mathrm{~S}$ & $\mathrm{I}$ & 0 & 0 & 0 \\
34 & $\mathrm{~S}$ & $\mathrm{I}$ & 0 & 0 & 0 \\
35 & $\mathrm{~T}$ & $\mathrm{I}$ & 0 & 0 & 0 \\
36 & $\mathrm{~T}$ & $\mathrm{I}$ & 0 & \\
& &
\end{tabular}

One should stress that supply interruption services due to non-payment do not cause any kind of regulatory penalty to the utility by not meeting some kind of standard, because in Brazil there is no standard regarding shut-off clients. It is up to the utility to reduce the amount of pending electricity bills, in order to diminish its commercial losses. So the utility usually prioritizes the customers who have greatest total debit.

How quick the commercial services should be assisted depends on the importance of the client to the utility as well, according to the classification index. Primary importance means that this type of customer is the most important one to the utility, followed by the secondary client and by the tertiary one.

The supply restoration services must usually be assisted as soon as possible, mainly if it affects a large number of customers.

For this study it was considered that the time spent to assist a supply interruption services due to non-payment is 30 minutes. For the other services the time spent is 1 hour.

Thus, the fictitious situation was given to CEMAR's dispatch operator so he could dispatch the crew teams in order to meet the SCs using the current method. The result obtained is shown on Table IV.

TABLE IV

DISPATCH MADE BY THE COMPANY'S OPERATOR

\begin{tabular}{cccc}
\hline \hline SC sequence & Team 1 & Team 2 & Team 3 \\
\hline $\mathbf{1}$ & 06 & 04 & 16 \\
$\mathbf{2}$ & 08 & 02 & 07 \\
$\mathbf{3}$ & 10 & 01 & 26 \\
$\mathbf{4}$ & 09 & 05 & 17 \\
$\mathbf{5}$ & 15 & 03 & 19 \\
$\mathbf{6}$ & 28 & 24 & 18 \\
$\mathbf{7}$ & 25 & 33 & 21 \\
$\mathbf{8}$ & 27 & 31 & 20 \\
$\mathbf{9}$ & 13 & 29 & 11 \\
$\mathbf{1 0}$ & 22 & 12 & \\
$\mathbf{1 1}$ & & 34 & \\
\hline \hline
\end{tabular}

Unattended SCs: 14, 23, 30, 32, 35 and 36

As predicted, CEMAR's solution has some problems, once it was intuitively built and could not take into account all the problem's constraints. In this example, the dispatcher did not consider the displacement time, so it would not be possible to meet all the SCs pointed out. Also, he forgot that SC 15 could only be met at 3 p.m. and tried to meet it earlier.

In order to measure the effectiveness of CEMAR's solution, its dispatch was simulated by the new algorithm for comparison. The simulation, however, took into account the crew teams shift duration and all the other constraints. In the new result, the SCs 11, 13, 22, 25 and 27 could not be met as well as the other SCs unattended by the previous solution. The final score of the solution was [852.04 | 3045.09].

The other algorithms presented similar solutions among them but very different from the current method. The final score calculated for the solution using the sequential, deterministic-concurrent, random-concurrent and simultaneous are respectively: [258.84 | 3621.93], [275.98 | 3603.69], [258.84 | 36017.52] and [258.84 | 30618.62]. Thus, the solutions proposed by the project were able to better achieve the company's goals.

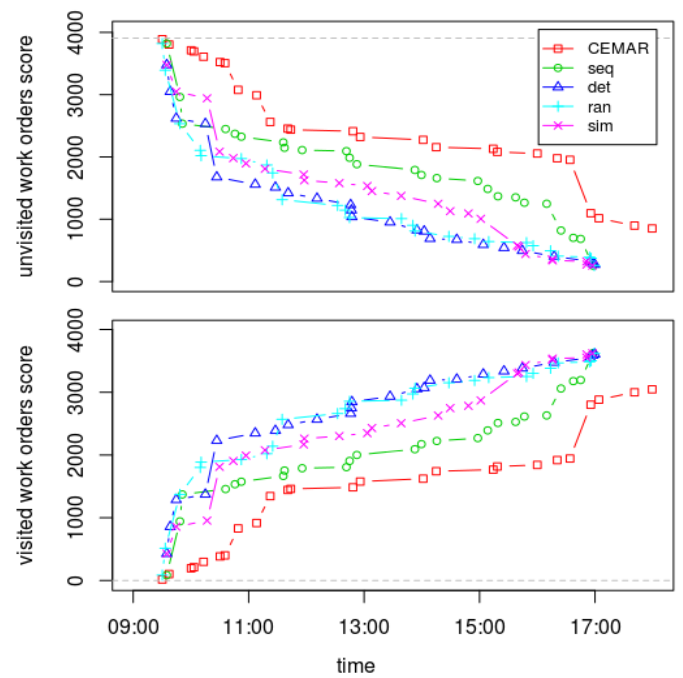

Fig.1: On the top unattended SCs (work orders) scores throughout the day; On the bottom visited SCs (work orders) scores throughout the day. "Seq" refers to sequential, "det" refers to deterministicconcurrent, "ran" refers to random-concurrent and "sim" refers to simultaneous. 
Fig. 1 is a graph showing the scores of each algorithm and CEMAR throughout the day. One can see that the algorithms solutions presented best scores all day long.

\section{B. Second Situation}

This situation will focus on exploring possible limitations of the 4 ACO variations. In this case, the crew teams are not equal. Now, team 1 is much faster than team 2 and 3 . All of them have a 24 hours shift. Also, just 3 SCs were created. They are described on Table V and VI.

TABLE V

PENDING COMMERCIAL SERVICES

\begin{tabular}{cccccc}
\hline \hline $\begin{array}{c}\text { Commercial } \\
\begin{array}{c}\text { Services (all } \\
\text { reconnection) }\end{array}\end{array}$ & $\begin{array}{c}\text { Client im- } \\
\text { portance }\left({ }^{1}\right)\end{array}$ & Type of request & $\begin{array}{c}\text { Client's average bill } \\
\text { (US\$) }\end{array}$ & $\begin{array}{c}\text { Process started }\left(^{2}\right) \\
\text { (hours) }\end{array}$ & $\begin{array}{c}\text { Deadline } \\
\text { (hours) }\end{array}$ \\
\hline 01 & $\mathrm{~S}$ & Ordinary & $5,000.00$ & 1 before & 0 \\
02 & $\mathrm{~S}$ & Ordinary & $5,000.00$ & 1 before & 0 \\
\hline \hline
\end{tabular}

( $\left.{ }^{1}\right)$ P - Primary; S - Secondary; T - Tertiary

$\left.{ }^{2}\right)$ Dispatch time: 09:00 a.m. on December 5th 2015

TABLE VI

PENDING SUPPLY RESTORATION SERVICE

\begin{tabular}{|c|c|c|c|c|c|}
\hline Supply restoration services & $\begin{array}{c}\text { Clients } \\
\text { importance }\left({ }^{1}\right)\end{array}$ & $\begin{array}{c}\text { Complaints } \\
\left(^{2}\right)\end{array}$ & Recalls $\left({ }^{3}\right)$ & $\begin{array}{l}\text { Reincidences } \\
\left({ }^{4}\right)\end{array}$ & $\begin{array}{l}\text { Process started } \\
\text { before dispatch }\left(^{5}\right) \\
\text { (hours) }\end{array}$ \\
\hline 03 & $P$ & $\mathrm{G}$ & 10 & 0 & 2 \\
\hline \multicolumn{6}{|c|}{$\begin{array}{l}\left.{ }^{1}\right) \text { P - Primary; S - Secondary; T - Tertiary. } \\
\left({ }^{2}\right) \text { I - Individual request; G - Group of consumers request. } \\
\left({ }^{3}\right) \text { Number of telephone calls from the same client. } \\
\left({ }^{4}\right) \text { Number of times that the same fault ocurred within, for instance, a month. } \\
\left({ }^{5}\right) \text { Dispatch time: } 09: 00 \text { a.m. on December 5th } 2015 .\end{array}$} \\
\hline
\end{tabular}

For the sequential algorithm the result is very dependent on the crew team selection. In case team 1 is selected, the solution is very good because the fast team 1 will assist to all the SCs at a good speed and the final score will be good. However, if instead of it, 2 or 3 were selected, the result would be much worse. Another disadvantage is that this algorithm left two teams resting while just one worked.

When using the deterministic-concurrent algorithm, the limitation is caused by having to set a sequence in which the teams will be chosen. In some cases, the team of the turn is not the most suitable for the SCs left at that time and you have no choice but use it. The problem with the random-deterministic algorithm is similar. The difference is that the teams sequence is randomly set.

At last, the simultaneous algorithm seemed to be the most adaptive because it makes possible to choose the most suitable feasible team-SC pair that can be chosen at each time. The disadvantage of this method is a consequence of its adaptiveness: once it has to calculate the feasible team-SC pairs for all the available teams, it spends a larger computational processing time.

\section{CONCLUSION}

Dispatching crew teams is a very hard work, once it has to take into account the changing circumstances and the many possible variables. But at the same time it has great importance in keeping the electricity systems working.

Thus, this paper proposes to present a new method for automatic crew team dispatch in an electricity utility. It was based on the Ant Colony Optimization (ACO) algorithm, which has 4 variations: sequential, deterministic-concurrent, random-concurrent and simultaneous.

First of all, the 4 algorithms were compared to the current method used by the company (basically intuitively). All of them could achieve better the goals of the utility.

At last, the 4 ACO algorithms were implemented in a situation that would test their limitations. The sequential algorithm does not work well in cases in which a slower team is chosen to assist a set of service calls (SCs) while some faster teams are assigned to none. The concurrent methods showed similar problems between each other. In both cases, once a team is chosen, according to a defined sequence or randomly, the best feasible team-SC pair might not be chosen which would not lead to the best solution. Finally, the simultaneous case seemed to be the most adaptive one, because it considers, at each chance, all the feasible team-SC pairs and can choose the best one. However, it is consequently the one that spends more computational processing time.

\section{REFERENCES}

[1] Ke, Liangjun; Archetti, C.; Feng, Z. "Ants can solve the team orienteering problem." Computers \& Industrial Engineering, v. 54, n. 3 , 2008, pp. 648-665. http://dx.doi.org/10.1016/j.cie.2007.10.001

[2] Denis Bouyssou, Thierry Marchant, Marc Pirlot, Alexis Tsoukiàs, Philippe Vincke. "The lexicographic method," in Evaluation and decision models with multiple criteria: Stepping stones for the analyst, v. 86. [S.I.]: Springer Science \& Business Media, 2006, pp. 188-190. 